\title{
KAAPSE PREDIKANTE VAN DIE SEWENTIENDE EN AGTIENDE EEU.
}

Nooit of te nimmer het dit in die gedagte van die sestiende eeuse Reformatore opgekom om hulle van die Kerk af te skei en 'n nuwe Kerk te stig nie. Dit kon nie, want dit was onverenigbaar met hulle

36) Bijv. Deut. 13:6 vv.; $17: 2$ vv.

37) O.a. RASCHI.

38) Vgl. WNT IV, 271 A. 3 (Michaelis).

39) Vgl. Lev. 1:4, ,dat ten zijnen gunste aanvaard wordt" (nirsā lō) door Jahve.

118 
kerklike opvatting. CaLvyn beklemtoon dit op verskillende plekke in sy bekende Institutio Christianae Religionis dat soiets ongeoorloof en sondig is. In die "ootmoedige vermaning" wat hy in 1543 aan Keiser Karel $\mathrm{V}$ en die deurlugtige vorste gerig het wat in daardie jaar op die Ryksdag in Spiers vergader het, sê hy met klem „ons is nie van die Kerk afgeskei nie en ook nie van sy gemeenskap vervreemd nie". Daardie magtige beweging van die sestiende eeu was vir die Kerkhervormers 'n Reformasie en nie 'n Rewolusie nie. Vir hulle was daar maar een ware sigbare Kerk. En daardie Kerk was nie 'n bloot menslike vereniging wat op die wil van die gelowige mense rus nie, op die wil van hulle wat vrywillig by die Kerk aansluit nie. Nee, die Kerk is ' $n$ goddeike instelling, dit is die moeder van al die gelowiges waarvan mens hom nie mag afskei nie. Soiets as "n "vrywillige beginsel" het die Reformatore nie geken nie, net so min as 'n pluriformiteit van die Kerk. Hulle het vasgehou aan die een ware sigbare Kerk. Geen veelheid van Kerke nie, maar 'n Kerk vir vele, en hulle het die hele nasie, die hele volk vir die Kerk opgeëis. Waar die pluriformiteitsbeginsel op verskeuring en verbrokkeling van die Kerk uitloop, daar word deur die Volkskerk die eenheid gehandhaaf. Die Reformasie het soiets as Vrye Kerke nie geken nie. Die Roomse, Wederdopers, Geesdrywers. Libertyne en Sociniane was vir hulle ketters

Dit het in die Kerkhervorming nie om 'n hervorming van die Kerk as instelling gegaan nie maar in die eerste plek was dit 'n hervorming van die Religie. Hierdie Hervorming het hom dan ook nie openbaar deur $n$ nuwe kerkvorm aan te neem nie maar deur 'n Geloofsbelydenis op te stel. Dit was die leet van die Kerk wat gesuiwer moes word, gesuiwer van die Roomse dwaalleer. Die belydenis of leer het uit die aard van die saak 'n groot invloed op die kerkorganisasie gehad en daarom het daar noodwendig op die duur die invoering van 'n nuwe kerkorde op gevolg, 'n kerkorde in die breedste sin; want vir die Reformatore het die kerkorde sowel op die kerkbestuur as op die openbare erediens betrekking gehad.

In Nederland is die Geloofsbelydenis in 1561 opgestel. Dit het die Confession de Foi van die Franse Kerk enigsins gevolg. In Frankryk is van "Réforme" gepraat en daardeur het in Nederland die spraakgebruik van Gereformeerde Religie in swang gekom. Dit was die Religie, die Godsdiens, wat gesuiwer, omgevorm, hervorm moes word en daarom is die gesuiwerde Religie of Godsdiens aangedui as die Gereformeerde Religie of die Hervormde Godsdiens. Die woorde gereformeerd en hervormd is nie $n$ benaming waarmee ' $n$ bepaalde soort aangedui word nie, dit is nie van dieselfde a ard as Calvinisties of Lutheraans nie, maar dit wys op die handeling, die aksie van die Reformasie, die Kerkhervorming. Dit sien op 'n voortgaande daad, voortgaande tht op die huidige dag. Die Hervorming was dus nie 
'n eenmalige daad van die sestiende eeu nie maar 'n handeling vanaf die skepping tot nou toe, 'n voortdurende stryd teen die dwaalleer wat altyd wil insluip.

Dit was nie enkel en alleen vryheid van godsdiens wat die Hervormdgesindes in Nederland begeer het nie. Hulle wou nie 'n gesindte naas ander gesindtes in die Staat wees nie maar het geëis dat die Owerheid die Gereformeerde Religie sou erken en handhaaf as die enigste Religie van die enigste Kerk in die land. „Nooit heeft men zich voorgesteld," - skryf Dr. H. G. KLEYN') - „dat de Hervormde Kerk iets anders zoude zijn dan de Volkskerk, de eenige die als de ware Kerk aanspraak mocht maken op openbare uitoefening. Maar dit veronderstelt, dat dan ook alle Nederlanders tot deze Kerk behooren (al wil men de onwilligen uit beginsel niet dwingen zich bij haar aan te sluiten)".

Die Hervormde Kerk was met sy Gereformeerde Religie dan ook nie 'n nuwe Kerk nie. Dit was die historiese voortsetting van die Kerk wat in die sewende eeu in Nederland veral deur middel van Willebrord geplant is. Hierdie Kerk was die enigste deur die Owerheid erkende Kerk en het dan ook geen naam gehad nie. Alleen as daar twee of meer van dieselfde soort is, word 'n eienaam noodsaaklik om verwarring te voorkom. In Nederland het die Kerk in die sestiende, sewentiende en agtiende eeu nie 'n vaste eienaam gehad nie, daar was maar een Kerk en dit was die "publicque" Kerk, soos in Skotland van die „Established Church" gepraat is. Met Gereformeerde Kerk of Hervormde Kerk is alleen bedoel dat die Religie van die Kerk gereformeer, dat sy Godsdiens hervorm is.

Daar was ooreenkomstig Artikel 36 van die Nederlandse Geloofsbelydenis ' $n$ nou verband tussen die Kerk en die Staat. Die Staten Generaal van Nederland het die onkoste van die groot Sinode van Dordt in 1618 en 1619 gedra en deur 'n baie ruime finansiering dit moontlik gemaak dat die Bybel opnuut uit die grondtale vertaal is, waarvan die uitkoms die verskyning was van die beroemde StatenBybel in 1637 wat vir daardie dae 'n meesterwerk was. Die Woord van God bely deur die Hervormde Kerk was die behoud van die vryheid. Die owerheid het hierdie gedagte uitgespreek deur op die ou munte die weerlose Nederlandse Maagd te plaas as verteenwoordigster van die hele nasie. Met die een hand leun sy op die Skrif en in die ander hand hou sy die speer met die vryheidshoed; die Latynse randskrif lui: „Terwyl ons op die Bybel steun verdedig ons die vryheid". Dieselfde gedagte vind ons in Artikel 8 van die Grondwet van die ou Zuid-Afrikaansche Republiek: „Het volk eischt de meest mogelijke maatschappelijke vrijheid, en verwacht die van het

1) Vgl. Dr. H. G. KLeYN, Algemeene Kerk en Plaatselijke Gemeente, Dordrecht, 1888, bls. 11-37. 
behoud van zijn godsdienstig geloof". Op 2 Augustus 1862 het die Uitvoerende Raad van die Republiek verklaar dat onder die woorde "behoud van zijn godsdienstig geloof" verstaan moet word die behoud van die Nederduitsch Hervormde Kerk.

Die Staten Generaal van Nederland het dit in Januarie 1651 in die "Groote Vergadering" in die Riddersaal van Den Haag nogmaals bevestig toe verklaar is dat "de ware Christelijke Gereformeerde Religie, gelijck als deselve alomme in de publicque Kercken deser Landen jegenwoordigh werdt gepredickt ende geleert, mitsgaders in den jare sestien hondert negentien bij de Synode Nationael gehouden tot Dordrecht is bevestight" gehandhaaf sal word. Die Owerheid was die versorger van die "publicque" Kerk en het dit stoffelik gesteun. Van kerklike kant is as skriftuurlike grond hiervoor op Jesaja 49 vers 23 gewys: „Ende Koningen sullen uwe Voedster-heeren zijn”, waarby die Kanttekenare die volgende geplaas het: „De $\sin$ is, Dat de Koningen niet alleen haer tot de gemeijnte Christi sullen vervoegen: maer sij sullen oock hare macht ende outhoriteijt gebruijcken tot aenwas, ende bescherminge der selver".

So het dit tot aan die Omwenteling van 1795 gebly wat 'n radikale verandering teweeggebring het. Die Christelike Owerheid moes vir die neutrale Owerheid plekmaak en die band tussen die Kerk en die Staat is losgemaak, en al die ander gesindtes is ook as "Kerke" erken en met die .publicque" Kerk gelykgestel. Dit was van toe af noodsaaklik dat die Kerk voortaan een vaste eienaam moes dra en hierdie naam was Hervormde Kerk.

In die sewentiende en agtiende eeu het die Hervormde Kerk van Nederland na drie wêrelddele uitgebrei, na Asië. Afrika en Amerika. Hierdie verbreiding na die eerste twee genoemde wêrelddele is deur middel van die Verenigde Oos-Indiese Kompanjie moontlik gemaak wat in 1602 opgerig is met die Here Sewentien as Bewindhebbeis aan die hoof. Dit het deur die oktrooi wat dit van die Staten Generaal ontvang het, die handelsmonopolie ,.beoosten de Cape Bonne Esperance ofte deur de Strate van Magellanes" gekry, met die reg om daar .opten naem van de Staten Generael der Vereenichde Nederlanden ' met .Princen ende Potentaten" verbintenisse en kontrakte te maak, forte te bou, goewerneurs en regterlike amptenare aan te stel. In daardie deel van die wêreld was die Kompanjie dus feitlik die Nederlandse Owerheid. En net soos die Owerheid in Nederland die voedsterheer van die Kerk was en alleen die Gereformeerde Religie of die Hervormde Godsdiens erken het, so was die Bewindhebbers van die Kompanjie in die Ooste - en daaronder het ook Suid-Afrika geval die voedsterhere van die Kerk en het alleen die Gereformeerde Religie 
of die Hervormde Godsdiens erken en ook baie gedoen om dit te verbrei. Maar die Kompanjie was in die eerste plek ' $n$ handelsliggaam en die geestelike belange is dikwels diensbaar gemaak aan die stoflike belange. As handelsliggaam het dit as eerste taak gehad om te sorg dat daar winste gemaak sou word sodat die mense wat hulle geld daarin belê het behoorlike uitkerings kon kry. Dr. VAN BOETSELAar skryf in verband hiermee op bladsy 5 van sy ..De Protestantsche Kerk in Nederlandsch Indië (1947): ,Als dit in het oog gehouden wordt, zal het oordeel over het beleid der Compagnie, waartegen meer dan eens bezwaren moeten worden ingebracht, milder uitvallen, dan dit gewoonlijk geschiedt. Men stelle de vraag welk handelslichaam ter wereld ook maar in de verste verte voor de geestelijke belangen gedaan heeft, wat onze V.O.C. daarvoor geofferd heeft Zeer zelden heeft zij uit bezuinigingsoverwegingen, vooral in haar goeden tijd, iets nagelaten, dat van haar in het belang der Kerk gevraagd werd. $\mathrm{Z}_{\mathrm{ij}}$ heeft gedurende de twee eeuwen van haar bestaan ruim 900 predikanten geheel op haar kosten naar Indië uitgezonden en daarnaast eenige duizenden krankbezoekers en onderwijzers. $Z_{i j}$ heeft millioenen aan de behartiging dezer geestelijke belangen ten koste gelegd. Zonder haar tusschenkomst kon niets gedaan worden, waarvan het gevolg was, dat zij alles te betalen kreeg: den bouw van kerken, het aanschaffen van leermiddelen, het drukken van Bijbels en andere boeken en al wat verder noodig was. Onder de lange lijsten van personen, die voor gratificaties in aanmerking kwamen, komen ook de namen van verscheidene predikanten voor, die voor het verrichten van bijzondere diensten extra belooningen hebben gekregen. Krenterig was de Compagnie allerminst. $Z_{i j}$ eischte van haar dienaren een stipte gehoorzaamheid, maar zij zorgde over het algemeen goed voor hən, al waren de salarissen niet ruim

Uit levensbeschrijvingen van zendingsmannen als William Carey en Adoniram Judson ziet men wat deze ook nog in de 19de eeuw aan tegenwerking van de Engelsche East India Company te verduren hebben gehad en valt een vergelijking zeer ten gunste van onze V.O.C. uit."

Dit spreek vanself dat daar in die begin nie voldoende predikante gevind kon word om hierdie groot werk in wêrelddele buite Europa te doen nie. In Holland self was daar nog 'n groot tekort. Dit is dan ook daarom dat reeds in 1603 die toevlug tot sieketroosters geneem is. Prof. Dr. L. Knappert teken hulle as volg: „Gerecruteerd uit schoenmakers en turfdragers, bakkers en droogscheerders, wevers en korenstouwers, door de hoogen aan boord maar zelden gesteund, door de lagen ruw behandeld, arme gekwelde lieden, ongestudeerd en voor hun taak kwalijk berekend, al te vaak het heilige aanrakend met ongewijde handen, moesten $z \mathrm{ij}$, wanneer door bedorven water en garstig 
pekelvlees scorbuut of roode loop woedden, langs de kooien der lijders gaan om de gebeden voor de zieken te lezen. Des Zondags lazen zij uit den bijbel voor, bij de talrijke begrafenissen aan boord de litaniën voor de dooden." ${ }^{2}$ ) Nie altyd is hulle gesteun soos hulle gesteun moes word nie en meermale is hulle op vernederende wyse behandel. So lees ons dat ' $n$ onderkoopman in Tonchin eenkeer ' $n$ sieketrooster laat roep het om 'n sieke te kom troos en toe hy daar aankom en vra waar die sieke is, wys hulle op die leë brandewynvaatjie en sê : daar is die sieke. ${ }^{3}$ )

In 'n ou reisbeskrywing word vermeld hoedat op Saterdag 15 April 1623 die sieketrooster op die skip met een van die matrose baklei het waarop die kaptein van die skip. Willem Ysbrantsz Bontekoe, hulle altwee ,in de boeyen" laat sit het Maar die volgende dag was dit paasfees en toe het hy hulle weer altwee laat uithaal sodat die sieketrooster, wat in die verhaal "dominé" genoem word, die godsdiensoefening kon waarneem, waarna hy saam met al die ander skeepsvolk kon deelneem aan die maaltyd waarvoor op die vorige dag spesiaal 'n vark en 'n buffel geslag is. ${ }^{4}$ )

Later het dit egter beter geword, veral nadat die Klassis Amsterdam in Maart 1621 in liggaam in die lewe geroep het wat bekend gestaan het onder die naam van Deputati ad Res Indicas wat onder toesig van die Klassis die Indiese kerksake moes behartig.

Hierdie ou sieketroosters het, wat ook al die tekortkomings van sommige van hulle mag gewees het, belangrike dienste gedoen in tye toe die predikante skaars was. Daar was goeies onder hulle en met name kan hier genoem word die eerste twee sieketroosters wat aan die Kaap was.

Byna oral waar die ou Hollanders hulle voetstappe gesit het, is voorsiening gemaak om die Evangelie ook daar te bring. Op plekke waar nog nooit iets van die christelike godsdiens gehoor is nie het hulle Evangelie-predikers heen gestuur. In die "Classicale Acte" wat so 'n predikant ontvang het, is dan ook gesê dat hy aangestel word „om te Water en te Lande onderweegen ende insonderheyd ter plaatse die hem zal werden aengewesen, gekomen sijnde, Godes heylige Woord, vervat in de Schriften des Ouden ende Nieuwen Testaments, te prediken, de menschen, in Godes name, de bekeerings tot Godt, ende de versoeninge met $\mathrm{Hem}$, door het gelove in Jesum Christem te verkondigen: de Sacramenten, Doop en het Avondmaal, die de Heere als

2) Prof. Dr. L. KNAPPERT: Schets van eene Geschiedenis onzer Handelskerken, in Nederlandsch Archief voor Kerkgeschiedenis, 1928, bls. 104.

3) J. R. Callenbach: Justus Heurnius, een bijdrage tot de geschiedenis des christendoms in Ned. Oost-Indië, 1897, bls. 18.

1) Journael ofte Gedenckwaerdige beschrijuinghe vande Oost-Indische Reyse van Willem Ysbrantsz Bontekoe van Hoorn (eerst druk in 16481, bls. 441-42. 
zeegelen zijner genade heeft ingestelt, te bedienen; de gemeente Christi met openbare gebeeden voor te gaan, deselfde, nevens de Ouderlingen ende Diaconen aldaar, in goede discipline en ordre te regeeren en te houden, alles nae Gods Woord, ende in conformiteyt van de Nederlandtse Kerken, Confessien en Christelyke Catechismus; verzoecken dienvolgende aan alle die geene, dien dit sal werden vertoont, en tot dewelcke onsen gemelten Broeder komen sal, dat se denselven gelieven als een wettelijck beroepen Dienaar Christi erkennen, hem in eere te houden om sijn ampts wille: mede hem na alle vermogen behulplijk te wesen, ten eynde hij sijn voorsz. Ampt onverhindert en met blijdschap mag bedienen, tot grootmakinge van Godes Heyligen Naem, bekeeringe en zaligheyt van veele." ${ }^{5}$ )

Verskillende van hierdie predikante het onbekende vreemde tale aangeleer om te help om die Skrif en die Heidelbergse Kategismus daarin te kan oorsit. Hulle kerklike distrikte was dikwels baie uitgestrek en hulle moes lang togte en besoekreise maak waar groot gevare aan verbonde was. Baie van hulle het skipbreuk gely; ander is weer ve:moor. In 1661 en 1662 is vyf predikante op die eiland Formosa deur die inboorlinge onthoof, ${ }^{6}$ ) drie van hulle, ds. Petrus Mus, ds. Johannes Campius en ds. Arnoldus Winshemius, het in 1655 aan die Kaap gepreek en die sakramente bedien. Een predikant is selfs gekruisig terwyl hy op die vyfde dag daarna aan die kruis nog geleef het en eindelik dood is. $\left.{ }^{i}\right)$ Verskillende van hulle het deur hulle geestelike arbeid in streke met 'n moordende klimaat hulle gesondheid verloor en het 'n vroegtydige dood gesterf. Die Hervormde Kerk in Indië het sy martelare gehad!

Op tal van plekke is in die sewende en in die agtiende eeu deur hierdie predikante gemeentes van die Hervormde Kerk van Nederland gestig: in Rusland op plekke soos Moskou, Argangel, Tula, Petersburg. Odessa, Riga, ens.; in Amerika in Nuw-Nederland, Brasilië Guiana, Suriname, die Wes-Indiese eilande; in Afrika, in Angola, die kus van Guinea, Kaap die Goede Hoop, ens.; om van Indië nie eers te praat nie.

Toe Jan van Riebeeck na Suid-Afrika gekom het, is 'n sieketrooster, Willem Barents Wylant, met hom saamgestuur. Hy het elke aand na die ete 'n gebed gedoen en twee of drie psalmverse laat sing. Op Sondae het hy ' $n$ preek voorgelees en die jong matrose die kategismus-

5) So'n „Classicale Acte”, die aanstelling van ds. Lambertus Schlicher in 1723. is afgedruk in C. SPOELSTRA: Bowwstoffen II, bls. 40-41; die aanstelling van Ds. J. H. vON MANGER in 1790, in sy Nagelatene Leertedenen (1843) "voorbericht" bls. iv-vi.

6) C. A. L. van Troostenburg de Bruyn: De Hervormde Kerk in Nederlandsch Oost-Indie onder de Oost-Indische Companie, 1884, bls. 450.

7) Van Troostenburg de Bruyne, bls. 451. 
vrae laat opsê; die antwoorde moes hulle met tekste uit die Bybel bewys. Hy wou graag twee keer op 'n Sondag boekevat, maar Van Riebeeck het een keer genoeg gevind want die mense moes in die week hard werk en Sondae kon hulle rus. Dit klink vreemd, maar is tog nie so vreemd nie as mens bedink dat 'n godsdiensoefening in die sewentiende eeu soms tot drie uur agtermekaar kon duur. Maar Van Riebeeck was baie streng daarop dat hulle die een godsdiensoefening dan ook moes bywoon. Die wat eenkeer van 'n diens weggebly het het sy wynrantsoen verbeur, en as dit vir die tweede keer gebeur, het so 'n persoon 'n maand lank nie betaling gekry nie; en as dit die derde keer plaasvind, dan moes hy 'n jaar lank in die ketting sonder betaling harde arbeid verrig. Wylant moes altyd 'n gedrukte preek van 'n predikant voorlees en mog nooit self 'n preek maak nie. Toe hy later 'n preek uit sy kop geleer het en dit so voorgedra het omdat sy ö̈ swak was, soos hy gesê het, het die Kerkraad vanuit Batavia hom daaroor ' $n$ berisping toegedien. Hy moes nie vergeet dat hy nie predikant maar sieketrooster was nie, en ,'t behoorde hem wel bekend te zijn sijenen sickel in eens anderen oogst niet te slaan noch aan sich die eere te trecken, die tot nog toe hem nie toe ende comt."

Die seuntiie van Wylant wat op 6 Junie 1652 gebore is, was die eerste wit kind wat in Suid-Afrika die eerste lewensliq_aanskou het Die tweede een was Abraham van Riebeeck, die seun van Van Rieheeck wat tussen 17 en 18 Oktober 1653 gebore is en later Goewe-neur-Generaal van Ned. Indië was. Toe die mense op die eersvolgenda Sondag, 19 Oktober, algar in die fort na die preek geluister het wat Wylant voorgelees het en God vir die voorspoedige geboorte van die kind gedank het, het die Hottentotte buitekant 'n jong seun wat die vee opgepas het, doodgeslaan en byna al die beeste en skape gesteel.

Wylant het in 1656 na Batavia gegaan en nog in Desember van dieselfde jaar het hy 'n aanstelling op Malakka gekry waar hy vanaf die begin van 1657 gearbei het.

Die tweede sieketrooster aan die Kaap was Pieter van der Stael. Sy vrou was 'n suster van Jan van Riebeeck. Hy het op 5 Maart 1656 aan die Kaap gekom en sy werk dadelik aangepak en dit op 'n pligsgetroue wyse vervul. Hy het hom ook die lot van die slawe aangetrek en vir hulle begin skoolhou. In 1657 het hy aan die klassis Amsterdam 'n wissel van dertig gulde en agt stuiwers gestuur van geld wat met die avondmaaldienste deur predikante van verbygaande skepe gehou. gekollekteer was Die Bewindhebbers in Holland het dit egter afgekeur dat kollektegelde daarheen gestuur moes word en het gelas dat dit aan Van Riebeeck afgedra moes word om te bewaar of op rente uit te sit, sodat dit, wanneer nodig, ten behoewe van Kaapse arm mense kon gebruik word. Toe Van Riebeeck in 1662 die Kaap verlaat het en na Indië vertrek het, wou Van der Stael hom volg en het daarvoor 
in Holland toestemming gevra. Dit is hom gegee en in Mei 1663 het hy vertrek.

Van der Stael is opgevolg deur die sieketrooster, Ernestus Back. Hierdie aanstelling was nie 'n gelukkige nie. Sy lewenswandel het ergernis gegee en toe daar in Desember 1664 'n komeet verskyn het, het Zacharias Wagenaar - Van Riebeeck se opvolger - in hierdie „ijzelicken steert sterre aen den hemel" 'n bedreiging van God gesien weens die gedrag van die sieketrooster en het hy by die Goewerneur van Batavia op sy verwydering aangedring. Nog voordat daar antwoord op hierdie versoek gekom het, het Wagenaar op eie gesag Back met sy gesin op 'n skip geplaas en weggestuur en begin Mei is Jan Joris Graa in sy plek aangestel. Hierdie nuwe sieketrooster het voldoening gegee maar reeds 'n maand na sy aankoms is hy oorlede.

In 1665 het die Kaap sy eerste vaste predikant gekry en van toe af het die Oos-Indiese Kompanjie gesorg dat daar in die sewentiende en agtiende eeu onafgebroke deur die Hervormde Kerk van Nederland predikante na Suid-Afrika gestuur is. Hulle is op koste van die Kompanjie uitgestuur en verder besoldig en onderhou, en dit was die Kompanjie wat pastorieë gebou het waarin hulle kon woon en kerke waarin hulle kon preek. Maar die Kompanjie wou waarborge hê dat die regte persone aangestel sou word en moes eers die benoemings finaal goedkeur. Maar daar was nooit geskille oor die benoemings tussen die Kerk en die Kompanjie nie. Die predikante wat deur die Kerk aanbeveel is, is deur die Here Sewentien aangestel. In die orde van die amptenare van die Kompanjie het hulle die rang van onderkoopman gehad met al die voorregte daaraan verbonde maar hulle mog geen handel dryf nie. Dit was bloot 'n rang en vind sy vergelyking in die teenswoordige leër waar 'n predikant die rang van majoor beklee.

Van die predikante wat in die sewentiende en agtiende eeu aan die Kaap was, is agt in Wesfale gebore en een in 'n gebied meer oostelik. Hulle word soms "Duitsers" genoem net soos ook diegene van die Afrikaanse voorouers wat uit Wesfale afkomstig is. Partykeer word dit op grond van propagandistiese oorwegings gedoen soos die geval is in die vreemdsoortige boek van WERnER SCHMIDTPretoria, „Der Kulturanteil des Deutschtums am Aufbau des Burenvolkes" wat voor die Tweede Wêreldoorlog deur die Duitse gesantskap in Suid-Afrika as propaganda-lektuur rondgestuur is. Maar so 'n voorstelling van sake is nie alleen fout nie, dog verraai ook 'n ernstige gebrek aan kennis van die geskiedenis van Europa vóór 1800. Die proses van die staatkundige eenwording van Duitsland het in die negentiende eeu sy beslag gekry. Wat as gevolg van die optrede van Bismarck die Duitse Ryk geword het, was in die 17 e en 18 e eeu geen staatkundige nóg kulturele nóg taalkundige eenheid nie. Die Wes- 
faalse Land was taalkundig en kultureel meer Nederlands as HoogDuits en dit is in die sestiende eeu op nie geringe wyse versterk deur die groot getalle vlugtelinge uit Nederland wat op verskillende plekke gemeentes gestig het. Die eerste Nederlandse Nasionale Sinode wat in 1571 in Emden, die hoofstad van Oosfriesland, gehou is, het ' $n$ klassikale indeling ontwerp waarby die Wesfaalse gemeentes by die Nederlandse Kerk ingedeel is.

Die Wesfaalse Land $^{8}$ ) het uit 'n kompleks van gebiede bestaan: die hertogdomme en vorstedomme Gulik, Kleef, Berg, Minden, Verden, Nassau-Siegen, Nassau-Dillenburg, Oosfriesland, Meurs en Wesfale; die graafskappe Wied, Sayn, Schouwenburg, Oldenburg, Delmenhorst, Lippe, Mark, Bentheim, Bentheim-Steinford, Lingen, Tecklenburg, Hoya, Virnenburg, Diepholt, Spiegelberg, Rietberg. Pyrmont, Gronsfeld, Reckheim, Holtzappel, Blanckenheim, Gerolstein, Kerpen, Lommersum, Schleiden, en Hallermond; die Bisdomme Munster, Paderborn, Luik en Osnabrug; die stifte en abdye Corvey, Stablo-Malmedy, Werden, Cornelis-Munster, Essen, Thoren, Herford en Borscheid; die vrystede Keulen, Aken en Dortmond; en dan nog verskillende heerlikhede. Daar waar die bevolking in hierdie gebiede Kalvinisties was, is verbinding met die Hervormde Kerk van Nederland onderhou. terwyl baie studente, veral teoloë, na Nederlandse universiteite gegaan het om daar te studeer. Dit het sterk invloede uitgeoefen.

In Oosfriesland was 'n selfde bevolking as in Nederland. Daar is in Hollands gepreek, net soos in Lingen, 'n gebied wat aan die Staten Generaal behoort het en in 1578 an die Prins van Oranje oorgegaan het en wat taalkundig Hollands was en waar daar 'n akademie was vir die opleiding van predikante deur Oranje gestig. Spiegelberg en Meurs het ook aan die Oranjes behoort, Tecklenburg. Bentheim. Steinfurt en Mark was grootliks Hervormd en Nederlands. In Kleef was Hollandse kerke net soos in Emmerik, Wesel en Duisburg. In Duisburg was ook 'n akademie om predikante op te lei, veral vir die Kleefse, Markse, Bergse en Gulikse gebiede waar daar Hollandse gemeentes was en waar die Statebybel en die Psalmberyming van Datheen gebruik is. Dan was daar die verskillende Rynvestings waar die Staten Generaal na 1614 garnisoene en garnisoenskerke gehad het wat Hollandse gemeentes was.

Die predikante van hierdie Hollandse Wesfaalse gemeentes en die predikante in Nederland self is oor en weer beroep. So sien ons byvoorbeeld dat ds. Wesselius Pretorius wie se seun Johannes Pretorius die stamvader van die Suid-Afrikaanse Pretorius-geslag is, in 1653 van Ouddorp in Suid-Holland na Emmerik in Kleef gegaan het.

9) Vgl. Johan Hubner, W. A. Bachiene en Ernst Willem Cramerus: Algemeene Geographie of Beschrijuing des geheelen Aardrijks, derde deel, tweede stuk, bls. 773-916 (Amsterdam 1769). 
Dit was geen beswaar nie want die kerktaal van Emmerik was Hollands net soos in Ouddorp En netso kon predikante van die Wesfaalse Land regstreeks na die Kaap gaan sonder dat dit vir hulle nodig was om vantevore eers Hollands te leer soos die Skotse predikante wat in die negentiende eeu na Suid-Afrika gekom het, moes doen. Neem ds. J. W Hertzogenraedt wat in 1730 van die gemeente Gatrop in die Klassis Duisburg onder die hertogdom Kleef na Drakenstein gegaan het. Hy kon, nadat hy deur die Klassis Amsterdam benoem was, regstreeks na die Kaap gaan want die kerktaal van Drakenstein was dieselfde as die van Gatrop. So vind ons in 1764 'n Hollandse korrespondensie tussen die Kaapse kerkraad en die kerkraad van Gulik. Die kerklike berigte van hierdie Wesfaalse gemeentes, soos sinodale en gemeentelike nuus, is die hele agtiende eeu saam met die kerknuus van die Nederlandse gemeentes in die mandelikse Boekzaal der Geleerde Wereld gepubliseer, wat in daardie dae die kerklike maandskrif van die Hervormde Kerk van Nederland was. In die Wesfaalse Land was daar klassikale vergaderings en provinsiale en generale sinodes wat alles in Nederlands gehou is. Mens vind trouens tot ver buite die grense van Wesfale Hollandse gemeentes wat hul kerknuus in die Boekzaal gepubliseer het soos in Bremen, Hamburg, Nassau-Weilburg, Hanau, waarby nog die ", handelskerke" kom van Riga en ander plekke.

Hanau was 'n graafskap dig by Frankfort wat sterk onder Nederlandse invloed gestaan het. Graaf Philips Lodewyk se vader was 'n halwe broer van prins Willem die Swyger met wie se dogter Catharina Belgica hy getroud was. Hy het in 1597 en 1601 aan Hollanders verlof vir 'n vry kerklike lewe gegee en om net buite die ou Hanau 'n nuwe Hanau te bou. Hier het 'n bloeiende Hollandse gemeente bestaan wat lank sy Hollandse karakter bewaar het en waar altyd in Hollands gepreek is Eers in 1852 is naas die Hollandse ook 'n Duitse predikant beroep. Die vader van die Kaapstadse ds. J. P. Serrurier, naamlik ds. Lodewyk Serrurier, wat in 1688 in Amsterdam gebore is, was verskeie jare predikant in Hanau waar al vier sy predikant-seuns gebore is waarvan twee predikant was in Amsterdam, een in Den Haag en een, die reeds genoemde ds. J. P. Serrurier, predikant in Kaapstad. Die vader van 'n ander Kaapstadse predikant, ds. C. Fleck, kom ook uit dieselfde Hanau. Dit is histories fout om hulle Duitsers te wil noem.

Die proses van verduitsing het met die opkoms van Pruisen begin. Frederik Willem von Brandenburg, die Groot Keurvors, het alles gedoen wat hy kon om sy gebied tot bloei te bring. Hy was met 'n Oranje prinses getroud, Louisa Henrietta, dogter van Frederik Hendrik, en het in Leiden studeer. Deur Nederlandse koloniste het hy die landbou tot hoë bloei gebring. Hy was met sy vrou Nederlands van opvatting. Sy seun. Frederik, het koning van Pruisen geword 
en het na die dood van koning-stadhouder Willem III in 1702 aanspraak gemaak op die gebiede van die Oranjes in Wesfale en met die afwikkeling van die erfenis in 1732 het Lingen, Bentheim en Meurs onder Pruisen gekom. Ook ander Wesfaalse gebiede het langsamerhand Pruisiese besit geword, tot selfs Oosfriesland in 1744. Al hierdie gebiede is heeltemal verduits en die Hollandse taal leef nog slegs in dialek-vorm voort soos deur die volk as daaglikse taal gebruik word, soos in die Rynse "Schipper-gemeente" te Keulen") wat vanuit die sewentiende eeu bestaan en waar tot op die huidige tyd in Hollands gepreek word. Dit is volkome foutief om die hele bevolking van hierdie gebiede in die sewentiende en agtiende eeu reeds as verteenwoordigers van die Hoog-Duitse taal en kultuur te beskou, ewe foutief as om die sewentiende en agtiende eeuse blanke bevolking van SuidAfrika Engelse te noem omdat die Kaap in 1795 deur Engeland beset is.

S. P. Engelbrecht. 